\title{
Roteirização de veículos para o abastecimento de linhas de produção
}

\section{Routing of vehicles for material delivery to assembly lines}

\author{
Luiz Caccalano ${ }^{1}$ \\ Claudio Barbieri da Cunha ${ }^{1}$
}

\begin{abstract}
Resumo: Este trabalho trata do problema de roteirização de veículos para o abastecimento de linhas de produção. Nesse problema, peças estão armazenadas em um estoque central e devem ser transferidas para pontos de uso localizados ao longo da linha de produção. O ritmo de fabricação na linha de produção é suposto constante, o que torna periódica a necessidade de reposição das embalagens contendo as peças. Uma frota de rebocadores transporta as embalagens dispostas sobre plataformas com rodas, configurando um comboio. O objetivo do problema é roteirizar a frota de rebocadores, maximizando sua utilização e garantido o atendimento da demanda gerada pela linha de produção. O problema é comum a muitas empresas de manufatura de bens de consumo e possui impacto direto nos custos operacionais. A literatura sobre o tema é escassa e as soluções empregadas na indústria habitualmente se baseiam na experiência prática de operadores ou responsáveis pela movimentação de materiais. Para a solução do problema, é proposta uma heurística baseada em métodos de inserção, aplicada a um caso na indústria automobilística. A comparação entre a solução obtida e aquela formulada por operadores demonstrou ganho no número de rotas.
\end{abstract}

Palavras-chave: Roteirização; Logística; Sistema de abastecimento; Heurística.

\begin{abstract}
This work deals with the routing of vehicles for material delivery to assembly lines. In this problem, parts are stored in central depot to be distributed to points of use located along the production line. Production rate in the assembly line is considered constant, which means that parts are delivered to points of use periodically. The boxes or containers with parts are moved by a fleet of tow cars using wheeled towed carts. The objective of this problem is to determine a set of routes that use the tow cars, aiming to maximize their utilization while ensuring that the demand for parts along the assembly line is fulfilled. This problem is common to several companies and has direct impacts on material handling costs. This subject is not commonly found in the literature, and several companies use operator experience to determine the routes of tow cars. In this work, we propose a heuristic based on insertion and improvement procedures to find a good solution for the problem. The heuristic was applied to a real problem and yielded to the reduction of the number of routes when compared to manual solution.
\end{abstract}

Keywords: Vehicle routing; Logistics; Line feeding; Heuristic.

\section{Introdução}

Este artigo aborda o problema da roteirização de veículos para o abastecimento de peças a linhas de produção. Trata-se de um problema comum a muitas empresas de manufatura de bens de consumo, particularmente aquelas com linhas contínuas de montagem ou fabricação, sejam automatizadas ou dispostas em células, como no caso da indústria automobilística, de autopeças e de eletrodomésticos da linha branca. Nesses ambientes, uma gama de peças, de diferentes tamanhos, formatos, consumos e exigências de manuseio, deve ser transferida desde uma área de estoque, também chamada de supermercado (SM), até pontos de uso (PDU) localizados ao lado das linhas ou na periferia das células de fabricação. As peças são acondicionadas em embalagens e movimentadas sobre plataformas com rodas, as quais devem ser rebocadas por um veículo especial, o rebocador.

O objetivo do problema é roteirizar uma frota de rebocadores para o transporte das embalagens, buscando minimizar o número de veículos e a distância total percorrida. O ritmo de fabricação na linha de produção é suposto constante, o que torna periódica as necessidades de reposição das embalagens nos PDU. Os rebocadores são idênticos e possuem uma capacidade de transporte conhecida, de modo que o número de embalagens movimentadas a cada viagem é restrito. Restrições adicionais do problema incluem o deslocamento dos rebocadores seguindo regras de circulação e de parada para descarga e o comprimento máximo da composição resultante do agrupamento

${ }^{1}$ Programa de Mestrado em Engenharia de Sistemas Logísticos, Escola Politécnica, Universidade de São Paulo - USP, Caixa Postal 61584, CEP 05424-970, São Paulo, SP, Brasil, e-mail: 1caccalano@uol.com.br; cbcunha@usp.br

Recebido em Fev. 24, 2015 - Aceito em Ago. 05, 2015

Suporte financeiro: Nenhum. 
entre rebocadores e os carros rebocados que levam as embalagens.

Os custos operacionais da atividade de movimentação de materiais em uma planta industrial são significativos. Sule (2009) afirma que as atividades de movimentação podem superar $30 \%$ dos custos operacionais totais de uma planta de manufatura, e economias da ordem de $15 \%$ a $20 \%$ podem ser alcançadas mediante uma revisão desse processo. Do ponto de vista tático, Bozer \& Yen (1996) afirmam que um sistema de movimentação de materiais incapaz de disponibilizar peças no momento certo e nas quantidades corretas pode levar a sérias descontinuidades e perdas no processo de produção, ociosidade de equipamentos ou equipes, elevação dos estoques em processo ou a perda de prazos de entrega.

O problema proposto pode ser entendido como uma particularização do problema de roteirização de veículos (PRV). Segundo Cunha (2000), os problemas de roteirização de veículos pertencem à categoria NP-difícil (do inglês "NP-hard"), o que significa que possuem ordem de complexidade exponencial e exigem grande esforço computacional para a sua resolução, inviabilizando o uso de algoritmos exatos.

Na prática, devido à complexidade do problema, empresas se utilizam de procedimentos manuais para a determinação de rotas, baseados na experiência de operadores ou responsáveis pela movimentação de materiais. As soluções obtidas por esses procedimentos são aproximadas e, por vezes, superestimam o número necessário de rotas e as distâncias percorridas, além de apresentarem rotas desbalanceadas quanto à carga de trabalho dos rebocadores.

Este trabalho propõe uma heurística para a obtenção de uma solução para o problema e descreve sua implementação em ambiente de planilha eletrônica. Optou-se por este ambiente de modo a criar para os profissionais da área responsável pela movimentação da empresa uma ferramenta de interface familiar, capaz de gerar com rapidez soluções alternativas ou simulação de diferentes cenários de abastecimento. Estes aspectos são bastante relevantes visto que o ambiente de produção é caracteristicamente variável, sujeito a perturbações relacionadas ao ritmo de fabricação ou montagem, falta de componentes, mudanças na diversidade de produtos (mix), falhas e paradas de máquinas e sistemas automáticos, entre outras. Operacionalmente, esses fatores podem justificar uma reavaliação e redefinição periódica da programação de abastecimento ou rotas dos rebocadores, visando a melhor utilização destes recursos e garantia do atendimento.

Este artigo está organizado da seguinte forma: a caracterização do problema é apresentada na próxima seção; na seção 3 , apresenta-se uma revisão bibliográfica com foco no problema de roteirização de veículos em ambientes industriais. A seção 4 descreve a estratégia de solução, cuja aplicação a um caso real é mostrada na seção 5 . A seção 6 contém as conclusões e recomendações para estudos futuros.

\section{Caracterização do problema}

A Figura 1 mostra um exemplo de comboio utilizado para a movimentação de embalagens entre o supermercado de peças e os pontos de uso. Um operador conduz o rebocador seguindo uma rota fixa; ele também é responsável pela troca de embalagens no PDU, substituindo embalagens vazias por embalagens cheias; as embalagens vazias retornam ao SM para uso posterior. Uma vez no depósito, as embalagens vazias que retornam são identificadas e determinam o reabastecimento da peça, reproduzindo um sistema do tipo kanban, porém sem cartões. Em instalações fabris mais recentes, sinais eletrônicos gerados pelos operadores da linha instruem a necessidade de abastecimento do PDU. Dessa forma, estabelece-se um ciclo periódico e repetitivo de atividades, conforme demonstrado na Figura 2. Na chegada do rebocador ao supermercado, a existência de embalagens vazias ou sinais eletrônicos para reabastecimento determinam o carregamento da próxima viagem do rebocador. Duas estratégias são utilizadas para as saídas do rebocador a partir do supermercado:

1. Saídas em intervalos fixos e regulares, de forma que o rebocador apenas iniciará uma nova viagem ao final de um intervalo pré-estabelecido, por exemplo, a cada 1 hora ou a cada 30 minutos. Tal intervalo deve ser igual ou inferior ao intervalo entre abastecimentos do item mais frequente alocado na rota e o rebocador deve esperar o instante de saída mesmo que já existam solicitações de abastecimento.

2. Saída imediata, assim que novos abastecimentos sejam necessários. Se já existirem solicitações no momento de chegada ao supermercado, a saída será imediata.

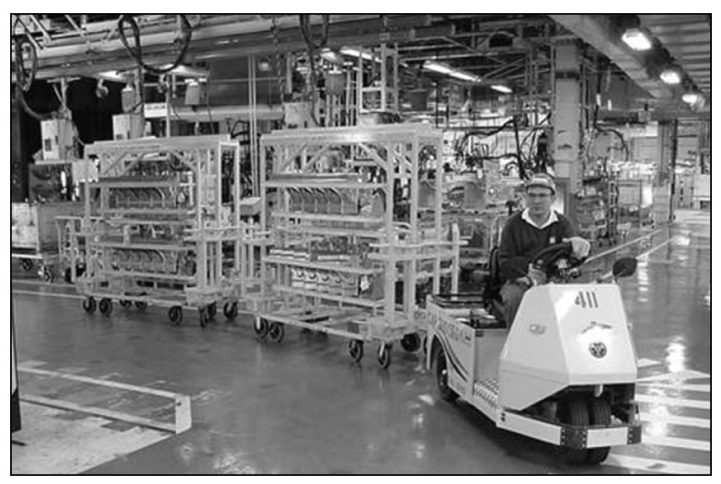

Figura 1. Exemplo do comboio de movimentação de embalagens. 


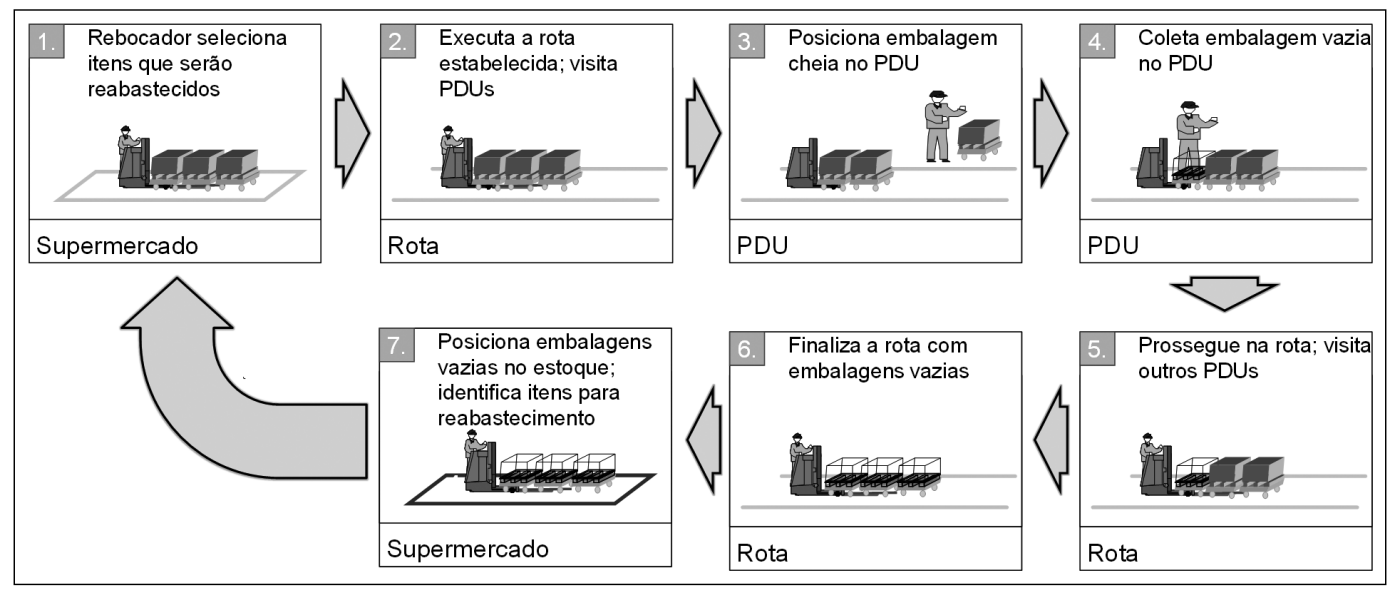

Figura 2. Ciclo de atividades de um rebocador em sua rota.

O tempo de viagem de um rebocador se compõe de quatro parcelas:

1. Tempo de preparação da carga da próxima viagem que é realizada no supermercado e abrange as atividades de (i) parar e descer do rebocador; (ii) identificar itens a serem separados; (iii) separar as embalagens correspondentes; (iv) montar o comboio; e (v) subir no rebocador e partir.

2. Tempo de deslocamento, que pode ser estimado como o quociente entre a distância total da rota e a velocidade do rebocador. Esta última pode ser considerada constante para fins de dimensionamento do sistema.

3. Tempo de manuseio das embalagens no PDU, que engloba as atividades de (i) parar e descer do rebocador; (ii) transferir uma ou mais embalagens cheias do comboio para suas posições no PDU; (iii) transferir uma ou mais embalagens vazias do PDU para o comboio; e (iv) subir no rebocador e partir.

4. Intercorrências diversas ocorridas no trajeto do rebocador, levando a reduções de velocidade ou paradas, motivadas por cruzamentos entre corredores, obstruções ou congestionamentos provocados por outros veículos com trajeto similar.

O intervalo entre abastecimentos $\left(T_{\text {reab }}\right)$ de uma embalagem no PDU é dado pela Equação 1:

$$
T_{\text {reab }}=1 / T P \times M I X \times Q / C_{e m b}
$$

Em que:

1. TP: taxa de produção da linha, expressa em produtos/min;
2. MIX: porcentual de produção de determinado produto em relação ao total produzido;

3. $Q$ : quantidade de peças consumida a cada ciclo de produção de um produto, expresso em unidades/produto ou quantidade/produto; pode ser obtido da lista de materiais do produto, também chamada de estrutura do produto ou Bill of Materials (BOM); descrito.

4. $C_{e m b}$ : capacidade da embalagem em que a peça está acondicionada, expressa em quantidade/ embalagem ou peças/embalagem.

O $T_{\text {reab }}$ de cada peça e o PDU de localização das peças compõem o chamado "Plano Para Cada Peça" (do inglês, Plan For Every Part - PFEP), como mostrado na Figura 3. Trata-se de uma relação exaustiva de todas as peças que serão abastecidas, incluindo dados como identificação, fornecedor, embalagem, quantidade na embalagem, PDU, intervalo entre abastecimentos, etc.

Considerando que uma rota normalmente transporta várias peças e, na maioria dos casos, abastece mais de um PDU, uma análise mais detalhada do PFEP permite inferir que:

1. O tempo de execução (duração) da viagem (Tviag) não deve superar o menor dos intervalos entre abastecimentos das peças associadas à rota. Neste trabalho, considera-se que o intervalo entre saídas do rebocador do supermercado (Tviag*) corresponde a este menor intervalo entre abastecimentos de PDUs que compõem uma rota.

2. Em diferentes viagens, os rebocadores podem transportar diferentes peças, sendo que as de menor intervalo entre abastecimentos estarão presentes 


\begin{tabular}{|c|c|c|c|c|c|c|c|}
\hline $\begin{array}{l}\text { Ponto de } \\
\text { Uso }\end{array}$ & Produto & $\begin{array}{l}\text { Throughput } \\
\text { (un/h) }\end{array}$ & Código Peça & Descrição da Peça & $\begin{array}{l}\text { Qtd/Prod } \\
\text { (un/prod) }\end{array}$ & $\begin{array}{l}\text { Qtd / Embal } \\
\text { (un/embal) }\end{array}$ & $\begin{array}{l}\text { Intervalo } \\
\text { reabastec } \\
(\min )\end{array}$ \\
\hline P1A1 & prod_DC & 12,6 & A171265E & SUPT - PBOX OTR S/PNL CS STEP & 1 & 20 & 95,2 \\
\hline $\mathrm{P} 1 \mathrm{~A} 1$ & prod_DC & 12,6 & A1712651 & REFORÇO CJ- PBOX PLTF \#4 CS & 1 & 20 & 95,2 \\
\hline $\mathrm{P} 1 \mathrm{~A} 1$ & prod_SC & 1,4 & A1712655 & REFORÇO CJ-PBOX PLTF CS & 2 & 8 & 171,4 \\
\hline $\mathrm{P} 1 \mathrm{~A} 1$ & prod_DC & 12,6 & A2101291 & PAINEL PBOX LADO\&W/H INT,LH & 1 & 30 & 142,9 \\
\hline P1A1 & prod_SC & 1,4 & A2101927 & PAINEL PBOX LADO\&W/H INT,LH & 1 & 4 & 171,4 \\
\hline $\mathrm{P} 1 \mathrm{~A} 2$ & prod_DC & 12,6 & A1722221 & PAINEL CJ-PBOX W/H CS & 1 & 30 & 142,9 \\
\hline $\mathrm{P} 1 \mathrm{~A} 2$ & prod_DC & 12,6 & A171265E & SUPT - PBOX OTR S/PNL CS STEP & 1 & 20 & 95,2 \\
\hline $\mathrm{P} 1 \mathrm{~A} 2$ & prod_DC & 12,6 & A2101296 & PAINEL PBOX LADO\&W/H INT,RH & 1 & 30 & 142,9 \\
\hline $\mathrm{P} 1 \mathrm{~A} 2$ & prod_SC & 1,4 & A2101922 & PAINEL PBOX LADO\&W/H INT,RH & 1 & 4 & 171,4 \\
\hline $\mathrm{P} 1 \mathrm{~A} 3$ & prod_DC & 12,6 & A1711702 & PAINEL-PBOX OTR SI-RH & 1 & 9 & 42,9 \\
\hline $\mathrm{P} 1 \mathrm{~A} 3$ & prod_DC & 12,6 & A1717791 & PAINEL CJ PBOX CS LATERAL,RH & 1 & 12 & 57,1 \\
\hline P1A3 & prod_DC & 12,6 & A2101E79 & PAINEL CJ PBOX CS LATERAL OTR,RH & 1 & 80 & 381,0 \\
\hline P1A4 & prod_DC & 12,6 & A1717792 & PAINEL CJ PBOX CS LATERAL,LH & 1 & 12 & 57,1 \\
\hline P1A4 & prod_DC & 12,6 & A2101E72 & PAINEL CJ PBOX CS LATERAL OTR,LH & 1 & 80 & 381,0 \\
\hline
\end{tabular}

Figura 3. Exemplo de PFEP, com indicação do PDU e intervalos entre abastecimentos.

em maior número de viagens e vice-versa. A peça cujo tempo entre abastecimentos determina Tviag* estará presente em todas as viagens do rebocador.

3. De forma geral, os intervalos entre abastecimentos de diferentes peças não são múltiplos entre si ou de Tviag*. A sequência de viagens da rota deve então ser planejada observando a melhor ocupação da capacidade do comboio e projetando a cada viagem os estoques de peças nos PDU, evitando a ocorrência de faltas.

Na prática, o ritmo e o mix de produção procuram ser estáveis, porém estão sujeitos a flutuações e mudanças, motivadas pela descontinuidade na entrega de peças por parte dos fornecedores ou problemas de qualidade e falhas ou paradas em equipamentos automáticos. Conforme mencionado anteriormente, tais ocorrências, várias delas de caráter aleatório, não são consideradas nesta abordagem: o ritmo de produção é considerado constante e o tempo entre abastecimento das peças é estável.

A função do sistema de abastecimento é atender às demandas da linha de produção sem provocar paradas por falta de peças. Entretanto, operacionalmente, procura-se otimizar o processo, visando os objetivos adicionais listados no Quadro 1.

Em contrapartida, uma série de restrições se impõe à operação do sistema, conforme mostrado no Quadro 2. A restrição 1 se refere à capacidade de transporte dos rebocadores e ao comprimento máximo admissível do comboio. Este último corresponde à soma dos comprimentos individuais das embalagens transportadas na viagem. A restrição 2 corresponde à prática usual de empresas do setor industrial brasileiro, no qual a atribuição dinâmica de rotas aos operadores, realizada a cada viagem do rebocador, não parece ter aceitação. Aparentemente, a flutuação ou a alteração de rotas a cada viagem pode estabelecer um cenário não muito claro sobre a responsabilidade do operador em manter os PDUs adequadamente abastecidos com o consequente risco de falta de peças nas linhas.

A restrição 3 amplia a reponsabilidade do operador da rota sobre o abastecimento de todas as peças de um mesmo PDU. A adoção desta prática também auxilia na minimização de congestionamentos, pois apenas um comboio poderá parar no PDU. A restrição é somente desejada, visto que pontos de uso com muitas peças podem isoladamente exigir capacidade de abastecimento superior àquela oferecida por apenas uma rota. Já a restrição 4 procura segregar áreas de atendimento com a perspectiva de manter rebocadores distantes uns dos outros e evitando, dentro do possível, a sobreposição de itinerários. A Figura 4 ilustra a restrição 5 , que trata do posicionamento de parada do comboio no momento de abastecimento. Ao se manter o lado direito do corredor para esta atividade, garante-se passagem livre para outros comboios vindos em direção contrária, evitando-se congestionamentos. A introdução da restrição 5 particulariza o problema tratado, pois, do ponto de vista de itinerário e distância entre dois pontos de uso, o deslocamento entre o primeiro e o segundo pode ser diferente daquele entre o segundo e o primeiro. Assim, a matriz de distâncias entre pares de pontos, necessária para a construção das rotas, será assimétrica.

As restrições 6 e 7 têm a ver com os movimentos permitidos e proibidos, conforme mostrado na Figura 5 e se relacionam à segurança e limitação técnica do sistema. A restrição 6 constitui uma prática comum em áreas de manobras de veículos; o procedimento evita o cruzamento entre fluxos que podem causar esperas tanto pelo veículo na rota que faz a curva como pelo veículo na rota que cede a passagem ao 
Quadro 1. Objetivos operacionais do sistema de abastecimento.

\begin{tabular}{|c|c|c|}
\hline Objetivo & Reflexos/Justificativa & Tipo \\
\hline $\begin{array}{l}\text { 1. Reduzir o número de recursos } \\
\text { necessários e maximizar sua utilização }\end{array}$ & $\begin{array}{l}\text { Redução de custos fixos e investimentos em rebocadores } \\
\text { e plataformas com rodas e custos recorrentes para sua } \\
\text { manutenção. }\end{array}$ & Prioritário \\
\hline 2. Reduzir a distância total percorrida & $\begin{array}{l}\text { Redução de custos variáveis relativos à utilização de } \\
\text { equipamentos. }\end{array}$ & Secundário \\
\hline $\begin{array}{l}\text { 3. Balancear carga de trabalho entre as } \\
\text { rotas estabelecidas }\end{array}$ & $\begin{array}{l}\text { Alinhado com boas práticas de gestão; perspectiva de } \\
\text { maior flexibilidade do sistema em situações de exceção. }\end{array}$ & Secundário \\
\hline
\end{tabular}

Quadro 2. Restrições operacionais do sistema de abastecimento.

\begin{tabular}{|l|l|c|}
\hline \multicolumn{1}{|c|}{ Restrição } & \multicolumn{1}{|c|}{ Justificativa } & Tipo \\
\hline $\begin{array}{l}\text { 1. Número máximo de plataformas rebocadas e } \\
\text { comprimento }\end{array}$ & $\begin{array}{l}\text { Restrições físicas para a movimentação, } \\
\text { capacidade de tração do rebocador e } \\
\text { segurança. }\end{array}$ & Obrigatória \\
\hline 2. Rotas fixas por rebocador & Atribuição de responsabilidade ao operador. & Obrigatória \\
\hline $\begin{array}{l}\text { 3. Peças de um mesmo PDU na mesma rota } \\
\text { 4. Proximidade entre os PDUs de uma mesma } \\
\text { rota }\end{array}$ & $\begin{array}{l}\text { Movimentação do rebocador em regiões } \\
\text { concentradas da área de produção. }\end{array}$ & Devejada \\
\hline $\begin{array}{l}\text { 5. Atendimentação do rebocador em regiões } \\
\text { direito da mão de direção do corredor }\end{array}$ & $\begin{array}{l}\text { Evitar carros na contramão; segurança; evitar } \\
\text { congestionamentos. }\end{array}$ & Desejada \\
\hline $\begin{array}{l}\text { 6. Rebocadores fazem curvas preferencialmenteria } \\
\text { para a direita }\end{array}$ & Minimizar o cruzamento de rotas; segurança. \\
\hline $\begin{array}{l}\text { 7. Rebocadores não fazem manobra de retorno } \\
\text { (em U) no corredor de onde vieram }\end{array}$ & Inviabilidade técnica, segurança. & Desejada \\
\hline
\end{tabular}

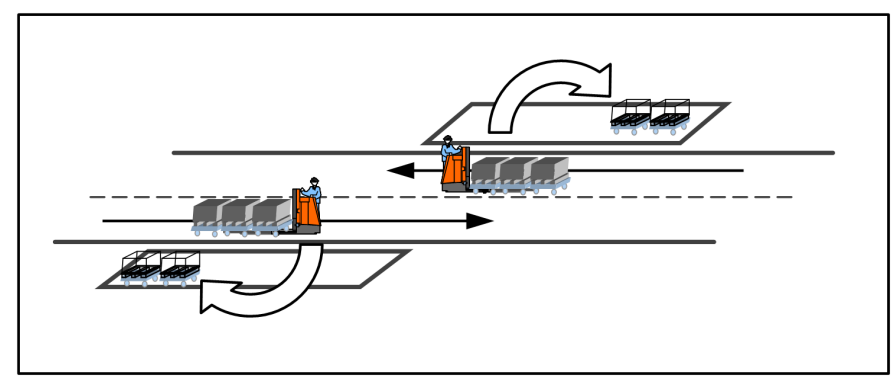

Figura 4. Atendimento do ponto de uso pelo lado direito do corredor.
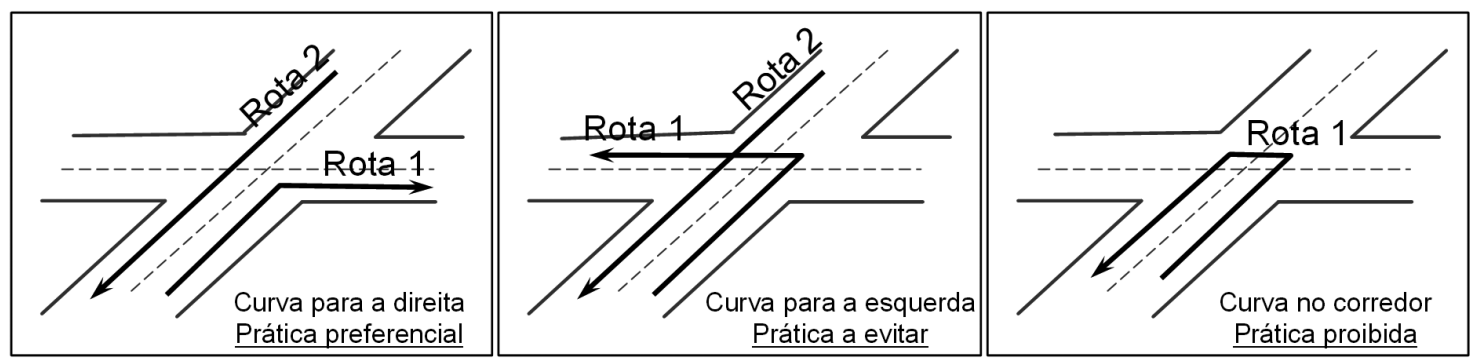

Figura 5. Curvas da rota preferencialmente para a direita.

cruzamento. Já a restrição 7 traduz um procedimento impraticável nas instalações comuns, visto que o raio de curva do comboio é relativamente grande, incompatível com a largura do corredor.

\section{Revisão bibliográfica}

Existe um consenso na literatura científica de que Dantzig \& Ramser (1959) tenham sido os primeiros autores a formular o problema da roteirização de 
veículos (Vehicle Routing Problem - VRP), motivados por uma aplicação real de distribuição de combustível a postos de venda. Em seu trabalho, os autores se referem ao VRP como uma generalização do TSP (do inglês, Travelling Salesman Problem) quando demandas nos postos de vendas e capacidade dos veículos são impostas ao problema. Segundo Assad (1988), a roteirização de veículos consiste em uma das histórias de maior sucesso da Pesquisa Operacional, face aos inúmeros trabalhos publicados desde então. Muitas variações do VRP foram estudadas, procurando incorporar ao problema original os mais diversos aspectos presentes nas aplicações reais, tanto na forma de objetivos como na forma de restrições, justificando diversas classificações dos tipos de problemas.

Wu \& Cunha (2008) afirmam que os problemas de roteirização de veículos são conhecidos pela sua complexidade e natureza combinatória. Torna-se, assim, impraticável a utilização de métodos exatos para a resolução de instâncias reais em tempos e esforços computacionais razoáveis. Os autores afirmam que, por vezes, é necessário utilizar métodos heurísticos, que não asseguram a obtenção de soluções ótimas, porém que exploram a região das possíveis soluções, de modo a obter uma boa solução viável, em tempos de processamento reduzidos. Cordeau et al. (2007) descrevem as principais heurísticas propostas para a solução do problema, dividindo-as em dois grupos: heurísticas clássicas e meta-heurísticas. Quanto às heurísticas clássicas, os autores se reportam ao trabalho de Laporte \& Semet (2002), que, por sua vez, detalham duas abordagens:

1. Métodos construtivos, em que o ponto de partida é uma solução vazia, ou rota sem clientes, na qual, por um processo iterativo e mediante um critério de inserção, clientes são adicionados. Como exemplo desta abordagem, cita-se o método das economias, proposto por Clarke \& Wright (1964).

2. Métodos que decompõem a resolução do VRP em duas fases, (i) agrupamento de pontos de atendimento próximos entre si que compõem uma rota; e (ii) roteirização, para a determinação da sequência de atendimento dos clientes pertencentes a cada grupo. O algoritmo de varredura (do inglês, sweep method), atribuído a Gillet \& Miller (1974) é um exemplo deste tipo de abordagem.

Ambas as abordagens são complementadas por métodos de melhoria da solução inicial. Muitas alternativas foram propostas, porém, em geral, se concentram em algoritmos de busca local, como o $\lambda$-opt de Lin (1965).
Segundo Cordeau et al. (2007), diversas meta-heurísticas foram propostas para a solução do VRP. Comparadas às heurísticas clássicas, as meta-heurísticas conseguem ampliar o espaço de pesquisa de soluções do problema e seu emprego, de forma geral, evita ótimos locais. Três classes de meta-heurísticas têm sido mais comumente utilizadas e pesquisadas para o VRP:

1. Baseadas em métodos de busca, incluindo simulated annealing, deterministic annealing e tabu search.

2. Baseadas em métodos populacionais, como o algoritmo genético.

3. Learning mechanisms, como as redes neurais e a otimização por colônia de formigas.

Conforme visto anteriormente na caracterização do problema objeto deste artigo, problemas de roteirização também surgem no contexto do ambiente interno de instalações produtivas, mais especificamente no abastecimento de linhas de produção. Uma boa referência sobre roteirização no contexto industrial é o trabalho de Hasle \& Kloster (2007), com foco na modelagem e nas heurísticas de solução de pontos de roteirização de veículos ricos (do inglês "rich vehicle routing problems") que surgem no contexto industrial de coleta e abastecimento. Os autores não focam em nenhum problema ou aplicação em particular, mas procuram fazer uma analogia com os problemas de roteirização que ocorrem na coleta e distribuição física de produtos. Segundo eles, exceto alguma aplicação específica em que o problema for de tamanho reduzido ou a estrutura particular o torne extremamente fácil de resolver, a única alternativa viável de solução em termos de algoritmo é por meio de heurísticas.

A obra de Baudin (2004) é uma boa referência. Nela é descrito em detalhes o abastecimento de linhas de produção no contexto moderno de logística enxuta (lean logistics), inclusive a infraestrutura física das instalações. O autor descreve os meios de transporte mais comumente utilizados, entre os quais, paleteiras, carrinhos manuais, transportadores contínuos, empilhadeiras, composições dotadas de rebocadores e AGVs (Automated Guided Vehicles), e discute as vantagens e desvantagens, os usos e aplicações gerais de cada um desses meios de transporte. $\mathrm{O}$ autor compara empilhadeiras e composições com rebocadores, reconhecendo a flexibilidade das primeiras, porém afirmando que são inadequadas quando há necessidade de entregas frequentes. Ele sugere que as composições com rebocadores são meios mais adequados, ainda que o uso de AGVs tenha crescido nas últimas décadas. 
Boas revisões bibliográficas sobre o roteamento e a programação de $\mathrm{AGVs}$ podem ser encontradas em Co \& Tanchoco (1991) e Qiu et al. (2002). No trabalho mais recente, Qiu et al. (2002) conceituam roteamento e programação e suas diferenças, revisam os principais algoritmos aplicados a tipos diferentes de problemas, incluindo a movimentação de contêineres em áreas retroportuárias, uma área muito importante da aplicação de AGVs, segundo eles; adicionalmente, mostram que os estudos sobre a movimentação de AGVs, desenho de redes e roteirização em ambientes industriais e não industriais foram intensamente investigados. Neste tipo de problema, em que os veículos não têm um condutor (ao contrário do problema objeto deste artigo), o controle de tráfego é uma questão fundamental para a sua operação. Os autores conceituam e descrevem os diferentes tipos de problema relacionados e classificam os principais algoritmos aplicados. Outras referências sobre roteirização e programação de sistemas AGV podem ser encontradas em Kim \& Chung (2007) e Nishi et al. (2007).

Por outro lado, conforme apontam Golz et al. (2012), o problema da roteirização de composições para o problema do abastecimento de peças em linhas de produção tem sido menos explorado, dando-se maior importância a estudos relativos ao balanceamento de linhas ou sequenciamento de produção

Vaidyanathan et al. (1999) trataram do problema de formulação de rotas para o transporte interno de peças em uma fábrica trabalhando sob o sistema JIT. O problema central é o atendimento da demanda por peças exigida por pontos de uso espalhados no ambiente de produção. A demanda por peças é constante ao longo do tempo e o atendimento é feito por uma frota homogênea de veículos a partir de um único depósito central. Esses autores parecem ser pioneiros no estudo do problema do abastecimento de linhas de produção e seu trabalho representa uma contribuição importante para o tema, tendo em vista a formulação matemática nele apresentada.

Choi \& Lee (2002) propõem um modelo de roteirização dinâmico para a solução do problema de abastecimento de linhas de montagem automobilística que, devido às suas características, permitem uma solução bastante particular. O foco do método se concentra nitidamente no atendimento, atribuindo penalidades proporcionais à antecipação ou atraso em relação ao instante ideal para o atendimento da demanda, atuando indiretamente sobre o estoque em produção. Com o auxílio de simulação de eventos discretos, os autores fazem uma comparação entre um sistema real convencional e outro utilizando o método proposto.

Golz et al. (2012) trataram do problema de abastecimento de peças em linhas de montagem de automóveis, em que, segundo os princípios de just-in-time, os pontos de estocagem na linha devem ser abastecidos frequentemente com peças retiradas de um almoxarifado central. Os autores propõem uma heurística para o estabelecimento das rotas de abastecimento que serão cumpridas a cada turno de trabalho, e que se baseia na decomposição do problema de planejamento em dois estágios: estimativas das necessidades de abastecimento a fim de gerar ordens de transporte em cada dia e turno e a consequente programação das rotas. $\mathrm{O}$ objetivo do método é a redução de recursos, particularmente o número de operadores no sistema, em contraposição ao sistema Kanban de controle de materiais, que operam de acordo com uma sinalização que transmite a necessidade imediata de reabastecimento. De acordo com os autores, umas das principais desvantagens do Kanban no abastecimento de linhas automotivas é que, no caso de falta de peças em pontos da linha, rotas emergenciais devem ser realizadas, aumentando a demanda de condutores das composições. Isso é particularmente crítico, segundo os autores, na produção de carros de luxo, que apresentam grande variabilidade nas necessidades de peças. Foram realizados experimentos considerando-se nove cenários de teste, que demonstram que a abordagem proposta, de natureza pró-ativa, permite obter melhores resultados que a abordagem reativa (Kanban) para cenários de tamanhos médio (25 estações) e grande (50 estações), possibilitando a redução de 1,47 condutores em média.

Emde et al. (2012) investigam o problema do abastecimento de peças em uma linha de produção de automóveis. Seu trabalho propõe um procedimento para a determinação do número de embalagens a ser carregado a cada viagem de uma composição responsável pelo abastecimento de pontos de uso e cuja capacidade de transporte é conhecida. O objetivo do problema consiste na redução dos estoques de peças nos pontos de uso. Em seu problema, as rotas de abastecimento e a programação de visitas aos pontos de uso já são conhecidas de antemão. O objetivo é determinar quais embalagens devem ser carregadas em cada viagem e pode ser relacionado ao problema de estoque-roteirização (do inglês inventory routing), que trata da distribuição repetitiva de itens para múltiplos consumidores a partir de um único centro de distribuição. Os autores propõem um modelo matemático que é aplicado a instâncias de teste a fim de avaliar as compensações (trade-offs) entre número de viagens, a capacidade de transporte da composição e o estoque de peças nos pontos de uso; nenhuma aplicação prática é reportada.

\section{Estratégia de solução}

A fim de se determinar uma boa solução inicial viável para o problema é proposta uma heurística construtiva inspirada na heurística de Solomon (1987), embora o problema não considere restrições de janela 
de tempo nos PDUs. O princípio básico é construir uma rota por vez, sequencialmente, selecionando clientes ainda não roteirizados e alocando-os à rota corrente. Quando não for mais possível inserir novos clientes na rota corrente devido à restrição de capacidade ou devido ao tempo total de viagem, uma nova rota é criada e o processo se repete até que não existam mais clientes a roteirizar. Métodos paralelos assumem que o número de rotas seja conhecido, normalmente com base no resultado da aplicação de uma heurística de construção sequencial; clientes não alocados são selecionados com base em algum critério de ordenação e alocados nas melhores rotas que ainda dispõem de capacidade. Para ambas as estratégias, torna-se necessário estabelecer:

- Um primeiro cliente, denominado semente, para cada nova rota que se crie. Os critérios para esta definição são vários e próprios do problema que se pretende resolver.

- Um critério que indique a cada iteração qual a melhor posição na rota de cada um dos clientes ainda não roteirizados em relação às rotas correntes. No caso do método sequencial, apenas uma das rotas é a corrente; no paralelo, todas são correntes.

- Um critério que selecione, a partir do critério anterior, o próximo cliente que será inserido na iteração corrente.

Segundo Potvin \& Rousseau (1993), os métodos sequenciais tendem a alocar os últimos clientes ainda não roteirizados de maneira mais dispersa, fazendo com o que as últimas rotas geradas sejam de baixa qualidade. Por outro lado, os autores mencionam que uma das dificuldades dos métodos paralelos é determinar o número inicial $K$ de rotas a serem utilizadas. Os autores sugerem a utilização do método sequencial de Solomon (1987) para a estimativa das $K$ rotas necessárias. Em um segundo passo, o método paralelo é aplicado, utilizando os primeiros $K$ clientes selecionados como clientes sementes. O método paralelo é repetido para $(K-1)$ rotas, ou seja, elimina-se uma rota, até que a solução se torne inviável.

A Figura 6 mostra a estratégia de funcionamento do método sequencial implementado neste trabalho. Pontos de uso ainda não roteirizados são tomados sequencialmente a partir de uma lista ordenada (o critério de ordenação está descrito mais a seguir) e alocados na rota corrente. Todos os pontos de uso da lista são testados até que, respeitadas as restrições de capacidade de transporte do rebocador e o tempo total de viagem da rota, um primeiro seja alocado; este procedimento corresponde ao chamado "first-fit algorithm". Uma nova rota é criada sempre que a rota corrente não puder absorver qualquer dos pontos não roteirizados. O método não garante homogeneidade na ocupação das rotas, em geral carregando mais as primeiras em relação àquelas criadas por último.

Inicialmente, o critério para ordenação dos pontos de uso considera os respectivos intervalos entre abastecimentos de suas peças $\left(T_{\text {reab }}\right)$, visto que o menor valor dentre os pontos a serem atendidos determina 0 intervalo entre viagens consecutivas do rebocador a partir do supermercado (Tviag*). Uma vez inicializada a rota corrente com um PDU, o critério de ordenação

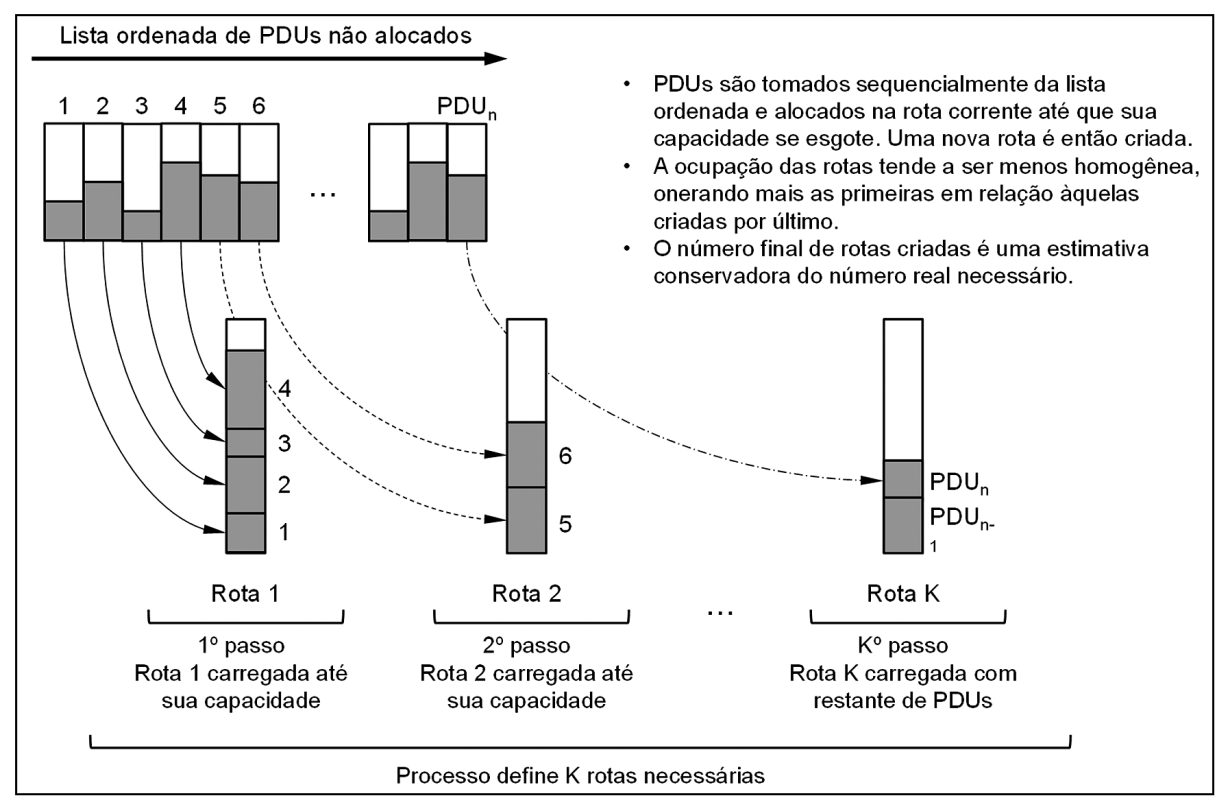

Figura 6. Método sequencial. 
é alterado, passando a considerar a distância entre os pontos candidatos e aqueles já alocados na rota; a cada iteração procura-se o ponto ainda não atendido mais próximo de algum dos pontos já alocados na rota, de forma que a inserção do novo ponto assegure o menor acréscimo na distância total percorrida na rota. Consideram-se ainda as seguintes premissas:

1. A velocidade de transporte é conhecida e constante: uma vez conhecida a distância entre dois pontos de uso da rota é possível determinar o tempo de deslocamento entre eles, compondo, juntamente com o tempo de manuseio de cada peça em cada PDU, o tempo de execução da viagem (Tviag). A matriz de distâncias entre os pontos de uso é determinada por um algoritmo específico que, além de considerar o acesso ao PDU pelo lado correto do corredor, também procura minimizar a ocorrência de curvas à esquerda nos itinerários. McBride (1982) e Benavent \& Soler (1999) estudaram a consideração de curvas em problemas de roteirização e seus trabalhos foram tomados como referência para a elaboração do algoritmo de caminho mínimo.

2. São conhecidos os tempos de manuseio das embalagens, tanto no supermercado como no PDU, os quais devem ser somados a Tviag a cada nova peça associada à rota.

3. O número máximo de embalagens que podem ser transportadas simultaneamente pelo rebocador e o comprimento máximo do comboio são fornecidos. As dimensões das embalagens, necessárias para o cálculo do comprimento do comboio, são conhecidas.

4. Para o cálculo da ocupação do rebocador, considera-se que cada embalagem transportada em uma viagem do comboio corresponde a uma unidade de capacidade. Assim, a peça que determina Tviag* corresponde a que será transportada em todas as viagens e ocupará uma unidade da capacidade do comboio. Uma segunda peça para a qual $T_{\text {reab }}=$ Tviag* será transportada em viagens alternadas, ocupando uma unidade da capacidade do comboio a cada duas viagens. Uma terceira peça com o mesmo $T_{\text {reab }}$ da segunda peça pode ser transportada em viagens alternadas, porém não coincidentes com aquelas da segunda peça. Como resultado, a ocupação do comboio a cada viagem resultará em dois, apesar de estar dando conta do transporte e abastecimento de três peças. No caso geral, os intervalos entre abastecimentos das peças não são necessariamente múltiplos entre si ou em relação a Tviag*. Torna-se assim necessário estimar a melhor sequência de viagens para o transporte das peças, estimando os estoques residuais a cada viagem e não permitindo ocorrência de faltas.

$\mathrm{O}$ esquema de funcionamento do método de inserção paralelo proposto é mostrado na Figura 7. Inicialmente, consideram-se as $K$ rotas determinadas

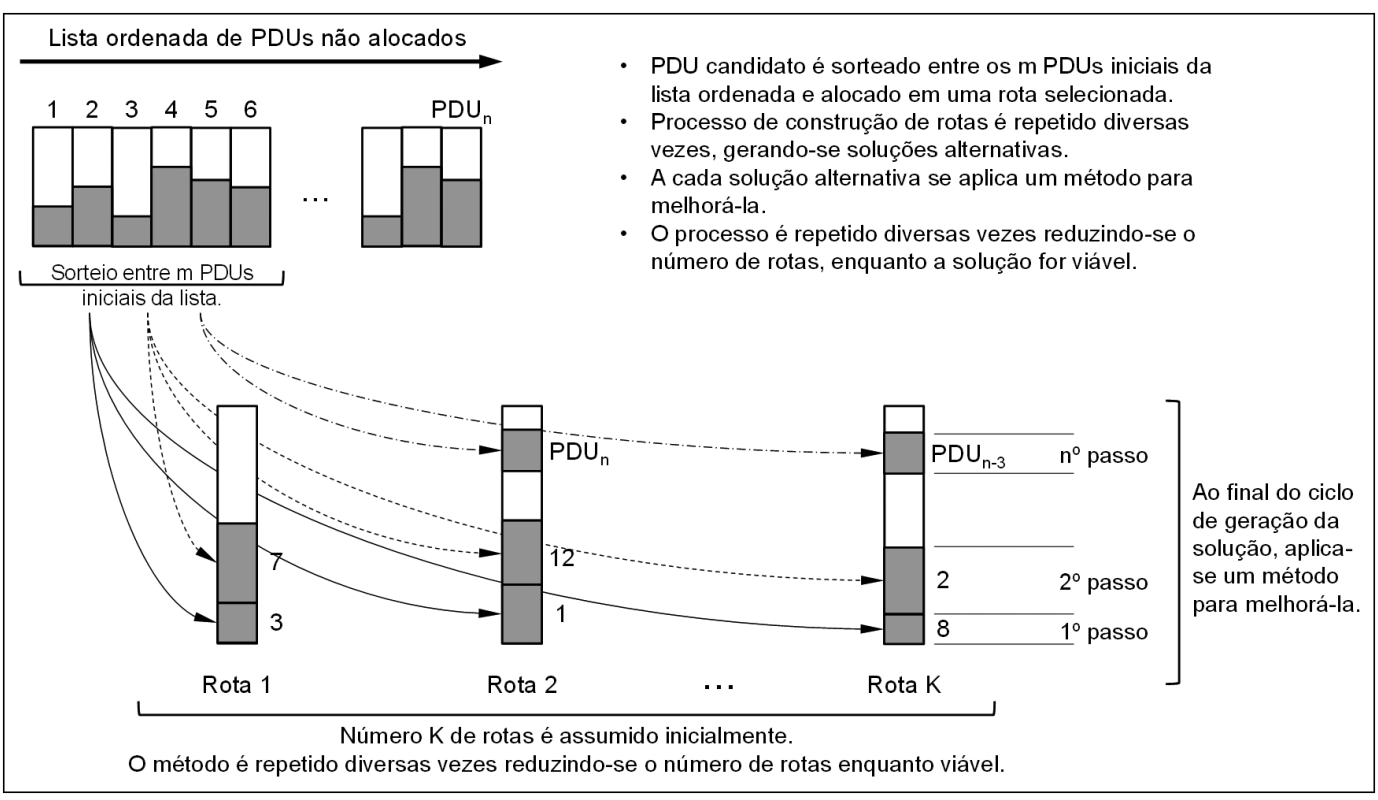

Figura 7. Método paralelo aprimorado. 
por meio do método sequencial; um PDU candidato é tomado da lista ordenada e alocado em uma rota selecionada que ainda disponha de capacidade para absorvê-lo. Inspirado na meta-heurística GRASP (do inglês Greedy Randomized Adaptive Search Procedure), proposta por Feo \& Resende (1995), e de forma a permitir a geração de soluções alternativas, os critérios de seleção do próximo ponto de uso candidato a ser inserido são distintos do método sequencial:

1. Na inicialização da rota, o ponto de uso candidato à alocação é sorteado entre os $m$ primeiros pontos ainda não atendidos, ordenados segundo ordem crescente de intervalo entre abastecimentos. O número $m$ de pontos deve ser igual ou superior ao número $K$ de rotas determinado pela heurística de inserção sequencial.

2. Outros pontos a serem inseridos nas rotas já inicializadas são escolhidos aleatoriamente entre os $m$ pontos iniciais da lista ordenada pelo critério de distância ou impacto sobre a distância total da rota.

3. O método é repetido diversas vezes e gera soluções alternativas, permitindo a combinação variada de pontos de uso em uma mesma rota.

4. Cada solução alternativa gerada é submetida a uma heurística de melhoria, a qual procura reduzir a distância total percorrida, além de melhorar a qualidade da solução. O critério de avaliação da qualidade da solução será discutido mais adiante no texto.

5. Soluções inviáveis são descartadas. Elas podem ocorrer quando as $K$ rotas correntes não mais puderem absorver pontos de uso, seja por falta de capacidade ou pelo tempo disponível para execução da rota, e ainda houver pontos não alocados.

Quanto ao critério para a seleção da rota onde alocar o ponto de uso candidato, as seguintes duas estratégias podem ser utilizadas:

1. Selecionar a rota mais ociosa ou de menor utilização até o momento da seleção. Este critério busca o equilíbrio de carga de trabalho entre as rotas da solução.

2. Selecionar a rota de maior utilização até o momento da seleção. Apesar de ser menos intuitivo, este critério se justifica, pois a concentração de carga em algumas rotas leva à diminuição de carga em outras rotas e estas últimas podem então ser combinadas no sentido de compartilharem os mesmos recursos. Em outras palavras, rebocadores podem alternadamente se responsabilizar por diferentes rotas cujos tempos de execução quando somados sejam inferiores ao menor intervalo entre abastecimentos dos itens pertencentes a essas rotas.

A solução final para o problema é obtida pela aplicação consecutiva dos métodos de construção de roteiros sequencial e paralelo:

Passo 1: o número de rotas é inicialmente estimado aplicando-se o método sequencial, em que $K$ rotas são construídas sequencialmente, uma a uma.

Passo 2: Uma vez encontrada uma solução factível $\operatorname{com} K$ rotas, aplica-se então o método paralelo, em que as $K$ rotas vão sendo construídas em paralelo, de maneira similar ao proposto por Potvin \& Rousseau (1993).

Passo 3: Se o método paralelo permitir gerar ao menos uma solução viável, reduz-se em 1 o número de rotas corrente, isto é, $K=K-1$, retornando-se ao Passo 2 acima a fim de se tentar encontrar uma solução viável com menos rotas.

Passo 4: Caso o método paralelo não permitir gerar uma solução viável com $K$ rotas, o algoritmo é interrompido. A solução do problema é a melhor solução até então obtida.

Tradicionalmente, os métodos de melhoria da solução objetivam a redução da distância total percorrida $\left(D_{t}\right)$. Entretanto, alguns autores destacam a importância da aparência ou "desenho" da rota, cunhando este aspecto qualitativo da solução de "atratividade visual" (ou "visual attractiveness"). Lu \& Dessouky (2006) comentam que operadores responsáveis por sistemas de entrega tendem a preferir rotas visualmente mais atraentes. Poot et al. (2002) citam que clientes e motoristas tendem a não gostar de rotas cujos itinerários se cruzem. Tang \& Miller-Hooks (2006) recomendam a inclusão de critérios visuais na busca da solução do VRP.

Neste trabalho, a avaliação da qualidade da solução utiliza a abordagem de Kim et al. (2006), os quais definem o indicador de forma da solução $\left(F_{m}\right)$, calculado pela Equação 2 e para o qual, um menor valor indica uma solução "visualmente mais atraente":

$$
F_{m}=\sum_{k=1}^{K} \sum_{i=1}^{n^{k}} \operatorname{dist}\left(P D U_{i}^{k}, P D U_{c}^{k}\right)
$$

Em que:

$K=$ número de rotas da solução;

$n^{K}=$ número de pontos de uso na rota $k$; 
$P D U^{K}{ }_{i}=i$-ésimo ponto de uso da rota $k$;

$P D U_{c}^{K}=$ ponto de uso mediano da rota $k$, definido como o mais próximo do baricentro dos pontos de uso da rota;

$\operatorname{dist}\left(P D U^{K}{ }_{i,} P D U^{K}\right)=$ distância euclidiana entre os pontos de uso.

Assim, uma vez que uma solução viável seja encontrada para um determinado número de rotas, $\mathrm{o}$ procedimento de melhoria busca a redução da distância total percorrida e do indicador de forma, o que pode ser conflitante (Poot et al., 2002). Na implementação, a solução é dita "melhorada" quando houver:

- Redução da distância total percorrida $D_{t}$.

- Redução do indicador de forma $F_{m}$, desde que o acréscimo em $D_{t}$ não supere um determinado percentual, inicialmente fixado em $20 \%$.

Tomando-se sequencialmente as rotas como maior valor de $F_{m}$ (a rota que se deseja melhorar, ou rota de referência) e também sequencialmente as rotas cujos itinerários possuam o maior número de corredores comuns à rota de referência (rotas candidatas), o procedimento avalia a melhor alternativa de melhoria dos indicadores após pesquisar:
- A realocação de PDUs, transferindo-os da rota de referência para uma rota candidata.

- O intercâmbio entre PDUs pertencentes a rotas distintas (referência e candidatas).

O procedimento se repete até que não se possam alcançar melhorias no indicador de forma $F_{m}$.

\section{Implementação e estudo de caso}

A heurística foi implementada em ambiente de planilha eletrônica MS-Excel, versão 2010, utilizando a linguagem VBA. Planilhas são amplamente empregadas em empresas de manufatura e sua utilização visa disponibilizar a usuários em geral um ambiente de fácil acesso e uma interface familiar. Para os processamentos, utilizou-se um computador com processador Intel Core $2 \mathrm{Duo}$, velocidade de $2 \mathrm{GHz}$ e $3 \mathrm{~Gb}$ de memória RAM, com sistema operacional Microsoft Windows Vista Home Premium - SP2.

$\mathrm{O}$ algoritmo proposto foi utilizado para a roteirização de rebocadores de abastecimento de uma linha de montagem de carrocerias de automóveis, cujo layout é mostrado na Figura 8. Três diferentes modelos de produtos são montados na linha, produzidos em diferentes proporções e exigindo o abastecimento de

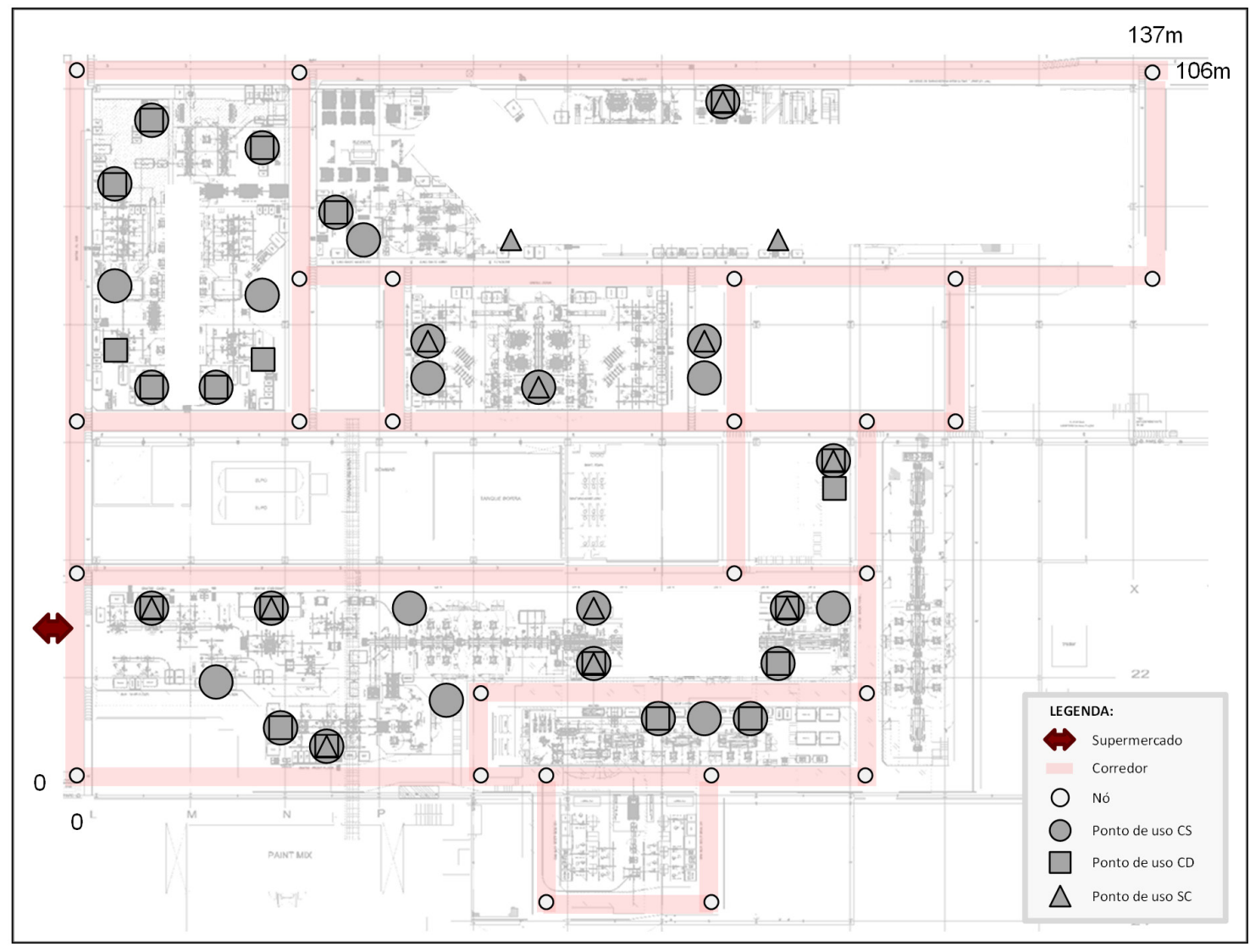

Figura 8. Rede de corredores e pontos de uso do estudo de caso. 
141 peças. Dados gerais e parâmetros deste estudo de caso são mostrados no Quadro 3. A duração do turno de trabalho é fornecida pela empresa em que se encontra a linha de produção. $\mathrm{O}$ número de abastecimento durante o turno é calculado a partir da duração deste e dos intervalos entre abastecimentos das peças. Tempos de ciclo associados às operações de manuseio de embalagem e paradas nos pontos de uso ou estoque são fornecidos pela empresa, fruto de um trabalho de cronoanálise dessas atividades.

A solução manual $(\mathrm{Sm})$ determinada pela área de movimentação de materiais da empresa utiliza 12 rotas para o abastecimento da linha de produção. Esta solução foi obtida a partir de um procedimento prático que inicialmente agrupa os pontos de uso por regiões. Para cada região propõe-se uma rota e a ela são associados os pontos de uso, tomados sequencialmente de uma lista ordenada pelo intervalo entre abastecimentos. A ocupação da rota é estimada pela soma das razões entre o intervalo de abastecimento da peça alocada e o tempo máximo de execução da rota. Uma nova rota é criada à medida que a rota corrente, devido à restrição de capacidade ou ao tempo de viagem, não possa mais absorver pontos de uso, ou quando uma nova região é abordada.

$\mathrm{Na}$ aplicação do algoritmo foram geradas duas soluções, obtidas de acordo com o critério de seleção da rota onde alocar o próximo ponto de uso candidato:

- Seleção da rota mais ociosa para alocação de pontos de uso durante a inserção paralela, buscando o equilíbrio de carga de trabalho entre as rotas da solução. Esta solução é chamada de balanceada $(S b)$.

- Seleção da rota mais ocupada para alocação de pontos de uso durante a inserção paralela, buscando a máxima concentração de carga de trabalho em algumas rotas e correspondente redução em outras, o que possibilita a combinação destas últimas, atribuindo-as a um mesmo rebocador. Esta solução é denominada concentrada $(S c)$.

A Tabela 1 apresenta uma comparação entre diversos indicadores da solução manual $(S m)$, balanceada $(S b)$ e concentrada $(S c)$. Além do número final de rotas, os seguintes indicadores são mostrados:

- $D_{t}$ : distância total percorrida pela rota durante o turno de trabalho, em $\mathrm{km}$.

- $F_{m}$ : indicador de forma da rota, em metros, correspondendo à soma das distâncias entre os PDUs e o centroide da rota.

- $D_{t}^{r}$ : média e dispersão das distâncias percorridas pelas rotas, em km.

- $F_{m}^{r}$ : média e dispersão do indicador de forma das rotas, em metros, correspondendo à soma das distâncias entre os PDUs e o centroide da rota.

- Ocup ${ }^{M E D}$ : valores mínimos e máximos das ocupações médias das rotas. Para $S b$ e $S c$, a

Quadro 3. Dados e parâmetros do caso real.

\begin{tabular}{|c|c|}
\hline Dado/parâmetro & Valor \\
\hline \multicolumn{2}{|l|}{ Características da rede de corredores $^{1}$} \\
\hline Número de nós & 36 \\
\hline Número de corredores & 40 \\
\hline \multicolumn{2}{|l|}{ Características de produção e abastecimento ${ }^{2}$} \\
\hline Número de pontos de uso & 36 \\
\hline Número de peças & 141 \\
\hline Intervalo mínimo entre abastecimentos & $33,3 \mathrm{~min}$ \\
\hline Intervalo máximo entre abastecimentos & $494,5 \mathrm{~min}$ \\
\hline Número de abastecimentos necessários durante o turno & 460 \\
\hline Turno de trabalho & $8 \mathrm{~h}$ \\
\hline \multicolumn{2}{|l|}{ Tempos de trabalho do operador ${ }^{3}$} \\
\hline Tempo de movimentação do operador no estoque & $0,51 \mathrm{~min}$ \\
\hline Tempo de movimentação do operador no PDU & $0,51 \mathrm{~min}$ \\
\hline Tempo de manuseio por embalagem no estoque & $0,97 \mathrm{~min}$ \\
\hline Tempo de manuseio por embalagem no PDU & $0,97 \mathrm{~min}$ \\
\hline \multicolumn{2}{|l|}{ Dados dos rebocadores ${ }^{4}$} \\
\hline Capacidade de transporte & $5 \mathrm{emb}$ \\
\hline Comprimento máximo do comboio & $7 \mathrm{~m}$ \\
\hline Velocidade média de deslocamento & $6 \mathrm{~km} / \mathrm{h}$ \\
\hline
\end{tabular}

${ }^{1}$ Obtidas a partir do layout da instalação fornecido pela empresa; ${ }^{2}$ Obtidos no PFEP fornecido pela empresa responsável pelo projeto;

${ }^{3}$ Fornecidos pelo departamento de engenharia industrial da empresa; ${ }^{4}$ Fornecidos pelo fabricante do rebocador. 
Tabela 1. Resultados comparativos entre soluções.

\begin{tabular}{|c|c|c|c|}
\hline Resultado & Manual Sm & Balanceada $S b$ & Concentrada $S c$ \\
\hline Número de rotas (-) & 12 & 11 & 10 \\
\hline$D_{t}(\mathrm{~km})$ & 30,5 & 32,9 & 37,0 \\
\hline$F_{m}(\mathrm{~m})$ & 711,6 & 536,3 & 675,1 \\
\hline$D_{t}^{r}(\mathrm{~km})$ & $2,5 \pm 2,2$ & $3,0 \pm 2,6$ & $3,7 \pm 1,1$ \\
\hline$F_{m}^{r}(m)$ & $59,3 \pm 102,6$ & $48,8 \pm 80,6$ & $67,5 \pm 44,1$ \\
\hline Ocup $p^{M E D}(-)$ & 1,3 a 6,7 & 3,4 a 5,0 & 3,0 a 5,0 \\
\hline $\operatorname{Ocup}^{M A X}(-)$ & 3 a 7 & 4 a 5 & 3 a 5 \\
\hline$U t i l^{M E D}(-)$ & $0,32 \pm 0,20$ & $0,29 \pm 0,18$ & $0,33 \pm 0,14$ \\
\hline Tviag* ${ }^{M E D}$ (min) & $68,7 \pm 54,8$ & $56,3 \pm 40,5$ & $46,7 \pm 16,7$ \\
\hline $\operatorname{Tviag}^{M E D}$ (min) & $18,9 \pm 10,6$ & $14,7 \pm 2,9$ & $14,6 \pm 3,0$ \\
\hline $\begin{array}{l}\text { Tempo processamento da solução } \\
\text { c/matriz de caminhos (s) }\end{array}$ & - & 107,0 & 92,0 \\
\hline
\end{tabular}

ocupação média de uma rota é calculada pela média da ocupação máxima de cada uma de suas viagens. Para $S m$, a ocupação média da rota é estimada pela soma das razões entre o intervalo entre abastecimentos das peças alocadas e o tempo máximo de execução da rota (Tviag*).

- Ocup ${ }^{M A X}$ : valores mínimos e máximos das ocupações máximas das rotas.

- Util ${ }^{M E D}$ : média e dispersão das utilizações das rotas, definida como a razão entre Tviag e Tviag*.

- Tviag* MED: média e dispersão dos tempos máximos de execução das rotas. O tempo máximo de execução de uma rota corresponde ao tempo entre abastecimentos de seu item mais frequente.

- Tviag ${ }^{M E D}$ : média e dispersão dos tempos de execução das rotas. O tempo de execução da rota é o tempo de execução de sua viagem mais longa, a qual combina o maior número de paradas em PDU e o abastecimento do maior número de peças.

- Tempo processamento da solução c/ matriz de caminhos: tempo de processamento da solução, em segundos. Neste caso, inclui o cálculo da matriz de caminhos mínimos.

A aplicação da heurística proposta gerou soluções com menor número de rotas que a solução manual que contava com 12 rotas. Na solução concentrada, a aplicação do algoritmo resultou em 10 rotas (redução de 16,7\%); houve aumento na distância total percorrida $D_{\text {te }} 30,5 \mathrm{~km}$ para $37,0 \mathrm{~km}(21,3 \%)$, porém a qualidade da solução mostrou ser melhor (redução do indicador de forma $F_{m}$ de 711,6 metros para 675,1 metros, correspondendo a um ganho de
5,1\%). A solução balanceada resultou em 11 rotas, também com aumento da distância total percorrida $D_{t}$ e melhoria do fator de forma $F_{m}$.

O aumento dos valores de distância percorrida total $D_{t}$ e por rota $D_{t}^{r}$ para as soluções do algoritmo são resultado de viagens mais frequentes, fato constatado pela redução da média de Tviag*. Já a variação do fator de forma das rotas $F_{m}^{r}$ é menor para as soluções geradas pelo algoritmo, mostrando uma tendência em gerar rotas mais compactas e de melhor qualidade também isoladamente. A comparação entre as médias das utilizações $\left(U t i l^{M E D}\right)$ mostra uma elevação do indicador para solução concentrada, certamente influenciada pela redução do número de rotas. A comparação entre as amplitudes de $U t i l^{M E D}$ mostra que a carga das rotas da solução manual é mais dispersa. O procedimento manual utilizado para a determinação das rotas é conceitualmente um método de inserção sequencial e demonstra as limitações apontadas por Potvin \& Rousseau (1993): tende a alocar os últimos clientes ainda não roteirizados de maneira mais dispersa, gerando assim rotas de baixa qualidade.

Para as soluções balanceada e concentrada, os valores de $U t i{ }^{M E D}$ também mostram dispersão; a solução concentrada apresenta inclusive um valor inferior à solução balanceada, o que parece conflitante quando se considera a motivação do nome dessas soluções. Em verdade, o método de melhoria adotado não considera a utilização da rota em seu processamento e este indicador tende a se deteriorar em relação aos valores obtidos no final da etapa de inserção paralela. Por outro lado, a opção pelo critério de seleção da rota mais carregada para a solução concentrada permitiu a redução do número de rotas. Entende-se que o critério possa ser utilizado como forma adicional de geração de soluções a serem submetidas ao método de melhoria.

O quadro ainda mostra que a média da ocupação média das rotas $\left(O c u p^{M E D}\right)$ é elevada, atingindo 4,6 embalagens tanto para a solução balanceada como para a concentrada, ambas próximas da capacidade 
de transporte dos rebocadores de 5 embalagens. Neste aspecto, o algoritmo demonstra consistência, procurando distribuir o abastecimento com o máximo de ocupação das viagens dos rebocadores. Por outro lado, percebe-se que a ocupação média das rotas na solução manual supera a capacidade, demonstrando que o procedimento manual não respeita integralmente esta restrição imposta ao problema. Na prática, viagens esporádicas adicionais são realizadas pelo rebocador, à medida que a falta de alguma peça seja sinalizada.

Por fim, o quadro mostra que as soluções foram obtidas em tempos de processamento bastante compatíveis com as atividades de planejamento da área responsável pela movimentação de materiais. No pior caso, o processamento completo, incluindo a determinação da matriz de caminhos mínimos entre os pontos de uso, foi de 107,0s.

\section{Conclusões e recomendações}

A aplicação da heurística proposta para a solução de um caso real de roteirização de veículos de abastecimento gerou soluções com menor número de rotas que a solução manual então implantada. Os tempos de obtenção das soluções foram significativamente menores que o tempo de execução do procedimento manual, estimado em horas conforme relato de operadores da empresa em que a linha analisada está implantada. A diferença de ordem de grandeza no tempo de geração da solução demonstra ser vantajosa, vista a possibilidade de execução de testes mais extensos quando do projeto de sistema de abastecimento ou mesmo de sua revisão diária, em face de mudanças de mix ou taxa de produção. A implementação em planilha MS-Excel representa uma facilidade adicional ao emprego da heurística em ambientes reais, vista a disponibilidade de tal ferramenta e a facilidade de uso por parte dos responsáveis pela atividade de manuseio de materiais.

A heurística proposta estabelece as rotas fixas a serem utilizadas, especificando os itinerários e pontos de uso a serem visitados periodicamente. Esta estratégia de operação é prática corrente nos ambientes industriais estudados. Outros trabalhos consideram a definição dinâmica e variável de rotas (Golz et al., 2012; Choi \& Lee, 2002) ou assumem que elas já são definidas (Emde et al., 2012).

A heurística se mostrou assim eficaz, porém existem oportunidades para estudos complementares futuros, como (i) a consideração de aspectos estocásticos associados a fatores como tempos de manuseio, tempos de deslocamento e flutuações nas taxas de produção; e (ii) a combinação de rotas com baixa utilização: rotas, cuja soma entre seus tempos de execução não supere o intervalo entre abastecimento do item mais frequente de qualquer uma delas, poderiam ser atribuídas a um mesmo rebocador.
A heurística também pode ser aprimorada de forma a ampliar a gama de situações encontradas em ambientes reais, incluindo a consideração de capacidade variável dos rebocadores, um maior detalhamento dos tempos de manuseio, especificando-os por tipo de embalagem ou mesmo em função dos recursos necessários, e a consideração de embalagens de tamanho modular, passíveis de serem transportadas sobre as plataformas com rodas em número superior a 1 , dependendo da combinação com outras embalagens na viagem.

\section{Referências}

Assad, A. A. (1988). Modeling and implementation issues in vehicle routing. In B. L. Golden \& A. A. Assad (Eds.), Vehicle routing: methods and studies (pp. 7-46). Amsterdam: Elsevier Science Publishers.

Baudin, M. (2004). Lean logistics: the nuts and bolts of delivering materials and goods. New York: Productivity Press.

Benavent, E., \& Soler, D. (1999). The directed rural postman problem with turn penalties. Transportation Science, 33(4), 408-418. http://dx.doi.org/10.1287/trsc.33.4.408.

Bozer, Y. A., \& Yen, C. (1996). Intelligent dispatching rules for trip-based material handling systems. Journal of Manufacturing Systems, 15(4), 226-239. http://dx.doi. org/10.1016/0278-6125(96)84549-3.

Choi, W., \& Lee, Y. (2002). A dynamic part-feeding system for an automotive assembly line. Computers \& Industrial Engineering, 43(1-2), 123-134. http://dx.doi. org/10.1016/S0360-8352(02)00071-2.

Clarke, G., \& Wright, J. W. (1964). Scheduling of vehicles from a central depot to a number of delivery points. Operations Research, 12(4), 568-581. http://dx.doi. org/10.1287/opre.12.4.568.

Co, C. G., \& Tanchoco, J. M. A. (1991). A review of research on AGVS vehicle management. Engineering Costs and Production Economics, 21(1), 35-42. http:// dx.doi.org/10.1016/0167-188X(91)90016-U.

Cordeau, J.-F., Laporte, G., Savelsbergh, M. W. P., \& Vigo, D. (2007). Vehicle routing. In B. Cynthia \& L. Gilbert (Eds.), Handbooks in operations research and management science (Vol. 14, Cap. 6, pp. 367-428). Amsterdam: Elsevier.

Cunha, C. B. (2000). Aspectos práticos da aplicação de modelos de roteirização de veículos a problemas reais. Revista Transportes da ANPET, 8(2), 51-74.

Dantzig, G. B., \& Ramser, R. H. (1959). The truck dispatching problem. Management Science, 6(1), 90-91. http://dx.doi.org/10.1287/mnsc.6.1.80.

Emde, S., Fliedner, M., \& Boysen, N. (2012). Optimally loading tow trains for just-in-time supply of mixed-model assembly lines. IEE Transactions, 44(2), 121-135. http:// dx.doi.org/10.1080/0740817X.2011.575442. 
Feo, T., \& Resende, M. G. C. (1995). Greedy randomized adaptative search procedures. Journal of Global Optimization, 6(2), 109-133. http://dx.doi.org/10.1007/ BF01096763.

Gillet, B. E., \& Miller, L. R. (1974). A heuristic algorithm for the vehicle dispatch problem. Operations Research, 22(2), 240-249. http://dx.doi.org/10.1287/opre.22.2.340.

Golz, J., Gujjula, R., Günther, H.-O., Rinderer, S., \& Ziegler, M. (2012). Part feeding at high-variant mixed-model assembly lines. Flexible Services and Manufacturing Journal, 24(2), 119-141. http://dx.doi.org/10.1007/ s10696-011-9116-1.

Hasle, G., \& Kloster, O. (2007). Industrial vehicle routing problems. In G. Hasle, K.-A. Lie \& E. Quak (Eds.), Geometric modelling, numerical simulation, and optimization (pp. 397-435). New York: Springer-Verlag Berlin Heidelberg.

Laporte, G., \& Semet, F. (2002). Classical heuristics for the capacitated VRP. In P. P. Toth \& D. Vigo (Eds.), The vehicle routing problem (SIAM Monographs on Discrete Mathematics and Applications, pp. 109-128). Philadelphia: SIAM.

Kim, B. I., Kim, S., \& Sahoo, S. (2006). Waste collection vehicle routing problem with time windows. Computers \& Operations Research, 33(12), 3624-3642. http:// dx.doi.org/10.1016/j.cor.2005.02.045.

Kim, K. S., \& Chung, B. D. (2007). Design for a tandem AGV system with two-load AGVs. Computers \& Industrial Engineering, 53(2), 247-251. http://dx.doi. org/10.1016/j.cie.2007.06.016.

Lin, S. (1965). Computer solutions of the traveling salesman problem. The Bell System Technical Journal, 44(10), 2245-2269. http://dx.doi.org/10.1002/j.1538-7305.1965. tb04146.x.

Lu, Q., \& Dessouky, M. M. (2006). A new insertion-based construction heuristic for solving the pickup and delivery problem with hard time windows. European Journal of Operational Research, 175(2), 672-687. http://dx.doi. org/10.1016/j.ejor.2005.05.012.
McBride, R. (1982). Controlling left and U-turns in the routing of refuse collection vehicles. Computers \& Operations Research, 9(2), 145-152. http://dx.doi. org/10.1016/0305-0548(82)90013-2.

Nishi, T., Morinaka, S., \& Konishi, M. (2007). A distributed routing method for AGVs under motion delay disturbance. Robotics and Computer-integrated Manufacturing, 23(5), 517-532. http://dx.doi.org/10.1016/j.rcim.2006.10.007.

Poot, A., Kant, G., \& Wagelmans, A. P. M. (2002). A savings based method for real-life vehicle routing problems. The Journal of the Operational Research Society, 53(1), 57-68. http://dx.doi.org/10.1057/palgrave/jors/2601252.

Potvin, J.-Y., \& Rousseau, J.-M. (1993). A parallel route building algorithms for the vehicle routing and scheduling problem with time windows. European Journal of Operational Research, 66(3), 331-340. http://dx.doi. org/10.1016/0377-2217(93)90221-8.

Qiu, L., Hsu, W.-J., Huang, S.-Y., \& Wang, H. (2002). Scheduling and routing algorithms for AGVs: a survey. International Journal of Production Research, 40(3), 745-760. http://dx.doi.org/10.1080/00207540110091712.

Solomon, M. M. (1987). Algorithms for the vehicle routing and scheduling problems with time window constraints. Operations Research, 15(2), 254-265. http://dx.doi. org/10.1287/opre.35.2.254.

Sule, D. R. (2009). Manufacturing facilities - location, planning, and design (3. ed). Boca Raton: CRC Press.

Tang, H., \& Miller-Hooks, E. (2006). Interactive heuristic for practical vehicle routing problem with solution shape constraints. Transportation Research Record, 1964, 9-18. http://dx.doi.org/10.3141/1964-02.

Vaidyanathan, B. S., Matson, J. O., Miller, D., \& Matson, J. E. (1999). A capacitated vehicle routing problem for just-in-time delivery. IIE Transactions, 31(11), 10831092. http://dx.doi.org/10.1080/07408179908969909.

Wu, L., \& Cunha, C. B. (2008). O problema da roteirização periódica de veículos. Transportes, 16(1), 5-16. 